\title{
RESPON ANTICIPATORY GRIEF ORANG TUA YANG MEMILIKI ANAK LEUKEMIA LIMFOBLASTIK AKUT (LLA) DI RSUP DR HASAN SADIKIN BANDUNG
}

\author{
Selvia Rahmayoza ${ }^{1}$, Ikeu Nurhidayah ${ }^{1}$, Aat Sriati $^{1}$ \\ Fakultas Keperawatan, Universitas Padjadjaran \\ ikeu.nurhidayah@unpad.ac.id / ikeu.nurhidayah@gmail.com
}

\begin{abstract}
Abstrak
Penyakit Leukemia Limfoblastik Akut (LLA) pada anak menyebabkan orang tua mengalami respon Anticipatory Grief tua berhubungan dengan kemungkinan kehilangan anak akibat prognosis yang buruk, survival rate yang rendah, pengobatan yang lama, dan resiko tinggi untuk relapse. Respon Anticipatory Grief normalnya berlangsung $<12$ bulan. Respon berduka yang buruk akan berdampak pada kualitas hidup anak dan orang tua, juga mempengaruhi pengambilan keputusan terhadap pengobatan anak. Tujuan penelitian ini adalah untuk mengetahui respon Anticipatory Grief yang dialami orang tua di RSUP Dr. Hasan Sadikin Bandung berdasarkan lama terdiagnosis. Penelitian ini adalah penelitian deskriptif kuantitatif dengan teknik total sampling dari populasi sebanyak 35. Instrumen dalam penellitian ini menggunakan Marwit-Mauser Caregiver Grief Inventory (MMCGI)-Childhood Cancer. Analisis data menggunakan distribusi frekuensi (frequensi, persentase, mean, dan standar deviasi). Hasil yang didapatkan adalah orang tua yang memiliki anak terdiagnosa 0-6 bulan memiliki intense berduka lebih tinggi dengan nilai mean $170.79 \pm 9.192$, dan orang tua yang memiliki anak terdiagnosa $>6$ bulan dengan nilai mean 155.19 \pm .479 . Profesional kesehatan harus mendorong orang tua untuk mendiskusikan perasaan terkait dengan penyakit anak mereka dan hasil yang potensial. Kebijakan rumah sakit perlu untuk memasukkan ketentuan dan promosi layanan palliative care sejak anak terdiagnosis, dan perawat perlu mendorong orang tua untuk bergabung dengan layanan kelompok pendukung.
\end{abstract}

Kata kunci: Anticipatory Grief, LLA, orang tua, anak

\begin{abstract}
Acute Lymphoblastic Leukemia (LLA) in children causes parents to experience Anticipatory Grief response associated with the possibility of losing children due to poor prognosis, low survival rate, prolonged treatment, and high risk for relapse. The Anticipatory Grief response normally lasts $<12$ months. A bad grieving response will have an impact on the quality of life of children and parents, also influencing decision making on children's treatment. The purpose of this study was to determine the response of Anticipatory Grief experienced by parents in Dr. Hasan Sadikin Hospital based on the duration of diagnosis. This is a quantitative descriptive study with a total sampling technique taken from 35 population of parents. This study used the Marwit-Mauser Caregiver Grief Inventory (MMCGI)-Childhood Cancer. Data analysis used frequency distribution (frequency, percentage, mean, and standard deviation). The results were parents whose children had been diagnosed with ALL for 0-6 months had a higher grieving intensity with a mean of $170.79 \pm 9.192$, and parents whose children had been diagnosed with ALL for $>6$ months showed the Griefing intensity with a mean value of $155.19 \pm .479$. Health professionals should encourage parents to discuss feelings related to their child's illness and potential outcomes. The hospital policy needs to include provisions and promotion of palliative care services since the child is diagnosed, and nurses need to encourage parents to join support group services.
\end{abstract}

Key words: Anticipatory Grief, LLA, parents, child 


\section{Pendahuluan}

Leukimia limfoblastik akut (LLA) merupakan jenis leukemia yang sering terjadi pada anak usia 2 tahun sampai usia 12 tahun dan menyebabkan kematian (Betz, 2009). Angka ketahanan hidup anak dengan LLA yaitu 5 tahun sejak anak mendapat pengobatan dengan kesintesan sekitar enam puluh persen, berbeda dengan Rumah Sakit Kanker Dharmais probabilitas ketahanan hidup 5 tahun hanya $22,6 \%$ (Simanjorang, Kodim, \& Tehuteru, 2012).

Pada anak yang terdiagnosis LLA, mendiskusikan tentang akhir kehidupan mungkin lebih menantang karena orangtua hampir selalu menjadi pengganti pengambil keputusan pada anak. Saunders telah menjelaskan kesan klinis bahwa berduka pada orang tua lebih parah dan lama dibanding berduka jenis lainnya. Antisipasi kehilangan anak dapat menghalangi diskusi tentang prognosis terminal dan dapat berdampak pada pengambilan keputusan dan integrasi perawatan paliatif (Wolfe, et al., 2000).

Menurut Kubler-Ross hampir
semua orang mengalami proses berduka dalam menghadapi kehilangan akibat penyakit terminal seperti kanker (Kubler-Ross, 1981). Respon berduka yang dirasakan sebelum kematian actual terjadi disebut respon Anticipatory Grief (Valizadeh, Zamanzadeh, \& Rahiminia, 2013). Rando mengemukankan Anticipatory Grief sebagai clinical dimension. Anticipatory Grief adalah fenomena yang meliputi proses berkabung, interaksi, perencanaan, dan reorganisasi psikologis yang dirangsang dan dimulai dari menanggapi kehilangan orang yang dicintai dan pengakuan kehilangan terkait masa lalu, sekarang dan masa depan (Rando, 2000 dalam Fulton, 2003).Marwit-Meuser membagi respon Anticipatory Grief pada Caregiver orang dengan kanker kedalam 3 dimensi. Diantaranya physical (jasmani), emosional, dan dimensi sosial tergantung pada tuntutan dan harapan perawatan saat ini. Dimensi-dimensi ini tercermin dalam tiga faktor yang Marwit and Meuser Caregiver Inventory(MMCGI): Personal Sacrifice Burden, Heartfelt Sadness \& Longing, Worry \& Felt Isolation (Marwit , Cibhnal, Dougherty, Jenkins, \& Shawgo, 2008).

Penelitian di Jordan tahun 2010 tentang Anticipatory Grief pada orangtua yang hidup dengan anak yang terdiagnosis kanker menyatakan orang tua yang anak memiliki anak terdiagosa kanker 0-6 bulan memiliki intens berduka lebih tinggi dari orang tua anak yang $>6$ bulan bulan terdiagnosis (Al-Gamal \& Long, 2010). Respon Anticipatory Grief yang dialami orang tua anak dengan kanker dipengaruhi oleh beberapa faktor yaitu lama terdiagnosis, pendidikian, pendapatan orang tua dan Dukungan sosial yang diperoleh kelurga (AlGamal, 2013; Burke et al., 2015; Rahmahkemala, Maslihah, \& Heryati, 2016).

Respon Anticipatory Grief yang tinggi pada orang tua akan mempengaruhi pengambilan keputusan dalam pemecahan masalah, yang dapat memiliki konsekuensi negatif pada keputusan medis yang menjadi tangung jawab orang tua (Fowler, Hansen, Barnato, \& Garand, 2015). Kondisi psikologis seperti Anticipatory 
Grief yang dialami orang tua merupakan faktor yang mempengaruhi kualitas hidup orang tua dan anak. Menurut Al- Gamal tahun 2013 orang tua dengan intenstitas antisipasi berduka yang tinggi dilaporkan dalam kualitas hidup yang rendah (Al-Gamal, 2013).

\section{Metode}

Jenis penelitian ini adalah penelitian kuantitatif deskriptif menggunakan metode survey dengan pendekatan Cross Sectional di mana data variabel akan dikumpulkan dalam waktu yang bersamaan, dan peneliti hanya satu kali mengambil data

terhadap responden.Instrumen yang digunakan untuk mengukur Anticipatory Grief dibuat oleh MarwitMauser Caregiver Grief Inventory (MMCGI) yang dimodifikasi oleh AlGamal et al. (2010) untuk Childhood Cancer.MMCGI-Childhood Cancer termasuk tiga faktor (subscale): personal sacrifice burden, merasa sedih dan kehilangan, dan cemas dan merasa terisolasi. Instrumen terdiri dari 50 item pertanyaan, dengan jawaban menggunakan skala linkert yaitu sangat tidak setuju memiliki poin 1 , tidak setuju poinnya 2 , agak setuju poinnya 3 , setuju poinnya 4 , dan sangat setuju poinnya 5 .

Uji validitas pada instumen ini menggunakan back to translate, uji konten, dan Face Validity kepada 5 orang tua yang memiliki anak dengan LLA. Instrumen ini sudah pernah digunakan di Jordan oleh Al-Gamal tahun 2010 dan sudah pernah diuji validitas dengan nilai $(\mathrm{r}=.91, \mathrm{p}<.001)$ menunjukan validitas yang baik. Uji Reabilitas Cronbach alpha coefficient untuk semua total instrument dari hasil penelitian Al-Gamal tahun 2010 adalah 0.95 , dan untuk setiap subscale yaitu 0.91 untuk personal sacrifice burden, 0.90 untuk perasaan sedih dan kehilangan, dan 0.86 untuk cemas dan merasa terisolasi.

\section{Hasil}

Tabel 1.Karakteristik Demografi Orang Tua yang memilki anak dengan leukemia limfoblastik akut (LLA) di RSUP Dr Hasan Sadikin Bandung $(\mathrm{n}=35)$

\begin{tabular}{|c|c|}
\hline Karakteristik & Presentasi (\%) \\
\hline $\begin{array}{l}\text { Jenis kelamin orang tua } \\
\text { Laki- laki } \\
\text { Perempuan }\end{array}$ & $\begin{array}{l}22.9 \% \\
77.1 \%\end{array}$ \\
\hline $\begin{array}{l}\text { Usia } \\
\text { Dewasa Awal (18-39 Tahun) } \\
\text { Dewasa Madya (40-59 Tahun) } \\
\text { Lanjut usia (60-70 Thun) } \\
\text { Lanjut usia tua (71-95 Tahun) }\end{array}$ & $\begin{array}{c}60 \% \\
37.1 \% \\
2.9 \% \\
0 \% \\
\end{array}$ \\
\hline $\begin{array}{l}\text { Pendidikan } \\
\text { Tidak sekolah } \\
\text { SD } \\
\text { SMP/SLTP sederajat } \\
\text { SMA } \\
\text { Perguruan Tinggi }\end{array}$ & $\begin{array}{c}2.9 \% \\
22.9 \% \\
42.9 \% \\
28.6 \% \\
5.7 \%\end{array}$ \\
\hline $\begin{array}{l}\text { Status perkawinan } \\
\text { Menikah } \\
\text { Bercerai } \\
\end{array}$ & $\begin{array}{c}97.1 \% \\
2.9 \% \\
\end{array}$ \\
\hline $\begin{array}{l}\text { Perkerjaan } \\
\text { Bekerja } \\
\text { Tidak bekerja } \\
\end{array}$ & $\begin{array}{c}31.4 \% \\
60 \%\end{array}$ \\
\hline $\begin{array}{l}\text { Berdasarkan } \\
\text { karakteristik demogra } \\
\text { meliputi usia, jenis ke } \\
\text { perkawinan, pendidikan, } \\
\text { Didapatkan hasil bah } \\
\text { besar orang tua yang } 1 \\
\text { dengan LLA di RSU } \\
\text { Sadikin Bandung dalam } \\
18-39 \text {, berjenis kelami } \\
\text { sebanyak } 27 \text { responde } \\
\text { sebagian besar tidak bek } \\
60 \% \text {, status perkawin } \\
\text { reponden berstatus } \\
\text { pendidikan sebagian be } \\
\text { berpendidikan } \\
\text { sebanyak } 42.9 \% \text { dan }\end{array}$ & $\begin{array}{l}\text { Tabel 1 } \\
\text { responden } \\
\text { amin, status } \\
\text { an pekerjaan. } \\
\text { a sebagaian } \\
\text { emiliki anak } \\
\text { Dr Hasan } \\
\text { rentang usia } \\
\text { perempuan } \\
\text { responden } \\
\text { ja mencakup } \\
\text { n mayoritas } \\
\text { enikah, dan } \\
\text { ar responden } \\
\text { MP/sederajat } \\
\text { erpendidikan }\end{array}$ \\
\hline
\end{tabular}


SMA sebanyak $28.6 \%$ dari keseluruhan responden.

Tabel 2. Respon Anticipatory Grief Pada Orang Tua Yang Memiliki Anak Dengan LLA di RSUP Dr Hasan Sadikin Bandung Berdasarkan Lama Terdiagnosis $(n=35)$

\begin{tabular}{cccc}
$\begin{array}{c}\text { Lama } \\
\text { terdiagnosis }\end{array}$ & \multicolumn{3}{c}{ Respon berduka } \\
& \multicolumn{3}{c}{} \\
\cline { 2 - 4 } & Mean & SD & Min-Max \\
\hline 0-6 bulan & 170.79 & 9.192 & $154-194$ \\
\hline$>$ 6 bulan & 155.19 & 11.479 & $122-172$ \\
\hline
\end{tabular}

Berdasarkan tabel 2 respon Anticipatory Grief orang tua yang memiliki anak dengan LLA di RSUP Dr Hasan Sadikin Bandung yang memiliki anak baru terdiagnosis $0-6$ bulan dan yang terdiagnosis $>6$ bulan dengan rerata total skor 170.79 dengan standar deviasi 9.192 menunjukkan nilai mean memiliki representasi baik dari seluruh data, dengan rentang nilai total skor tertinggi 194 dan terendah 154 , dan pada orang tua yang memiliki anak yang terdiagnosis $>6$ bulan rerata nilai total skornya 155.19 dan standar devisasi 11.479 dengan rentang nilai total skor tertinggi 172 dan terendah 122. Dari hasil penelitian didapat orang tua yang memiliki anak terdiagnosis $0-6$ bulan mengalami respon Anticipatory Grief yang lebih intens dari orang tua yang memiliki anak terdiagnosis $>6$ bulan.
Tabel 3 Respon Anticipatory Grief Dimensi Personal Sacrifice Burden Pada Orang Tua Yang Memiliki Anak Dengan Leukemia Limfobalstik Akut (LLA) di RSUP Dr Hasan Sadikin Bandung berdasarkan lama terdiagnosis $(n=35)$

\begin{tabular}{cccc}
\hline $\begin{array}{c}\text { Lama } \\
\text { terdiagnosis }\end{array}$ & $\begin{array}{c}\text { Respon berduka antisispasi } \\
\text { dimensi Personal Sacrifice } \\
\text { Burden }\end{array}$ \\
\cline { 2 - 4 } & Mean & SD & $\begin{array}{c}\text { Min- } \\
\text { Max }\end{array}$ \\
\hline 0-6 bulan & 61.84 & 6.858 & $50-75$ \\
\hline$>$ 6 bulan & 58.19 & 7.876 & $42-70$
\end{tabular}

Berdasarkan Tabel 3 pada dimensi Personal Sacrifice Burden pada orang tua yang memiliki anak dengan Leukemia Limfoblastik Akut (LLA) di RSUP Dr Hasan Sadikin Bandung berdasarkan lama terdiagnosis dapat dilihat bahwa orang tua yang memiliki anak terdiagnosis 0 6 bulan mengalami Anticipatory Grief yang lebih intense dengan rerata nilai total skor yaitu 61.84(6.858) dan orang tua yang memiliki anak terdiagnosis $>6$ bulan rerata nilai total skor yaitu 58.19(7.876), sedangkan standar deviasi menunjukan representasi nilai mean yang baik.

Tabel 4 Respon Anticipatory Grief Dimensi Merasa Sedih dan Kehilangan Pada Orang Tua Yang Memiliki Anak Dengan Leukemia Limfobalstik Akut (LLA) di RSUP Dr Hasan Sadikin Bandung berdasarkan lama terdiagnosis $(n=35)$

\begin{tabular}{cccc}
\hline $\begin{array}{c}\text { Lama } \\
\text { terdiagnosis }\end{array}$ & $\begin{array}{c}\text { Respon Anticipatory Grief } \\
\text { Dimensi }\end{array}$ \\
& \multicolumn{3}{c}{$\begin{array}{c}\text { Merasa Sedih dan } \\
\text { Kehilangan }\end{array}$} \\
\cline { 2 - 4 } & Mean & SD & $\begin{array}{c}\text { Min- } \\
\text { Max }\end{array}$ \\
\hline 0-6 bulan & 53.11 & 4.642 & $47-65$ \\
\hline$>$ 6 bulan & 44.56 & 3.346 & $39-50$ \\
\hline
\end{tabular}

Berdasarkan tabel 1.4 pada dimensi merasa sedih dan kehilangan pada orang tua yang memiliki anak dengan leukemia limfoblastik Akut 
(LLA) di RSUP Dr Hasan Sadikin Bandung berdasarkan lama terdiagnosis bahwa orang tua yang memiliki anak 0-6 bulan terdiagnosis mengalami berduka yang lebih intens dari orang tua yang memiliki anak terdiagnosis $>6$ bulan dengan perbedaan nilai mean yang tidak signifikan.

Tabel 5. Respon Anticipatory Grief Dimensi Cemas Dan Merasa Terisolasi Pada Orang Tua Yang Memiliki Anak Dengan Leukemia Limfobalstik Akut (LLA) di RSUP Dr Hasan Sadikin Bandung berdasarkan Lama Terdiagnosis $(n=35)$

\begin{tabular}{|c|c|c|c|}
\hline \multirow{2}{*}{$\begin{array}{c}\text { Lama } \\
\text { Terdiagnosis }\end{array}$} & \multicolumn{3}{|c|}{ Respon Berduka } \\
\hline & Mean & SD & $\begin{array}{l}\text { Min- } \\
\text { Max }\end{array}$ \\
\hline 0-6 bulan & 55.84 & 4.871 & 5 \\
\hline$>6$ bulan & 52.44 & 3.184 & $41-60$ \\
\hline
\end{tabular}

Berdasarkan tabel 1.5 dapat dilihat orang tua yang memiliki anak baru terdiagnosis LLA berduka pada dimensi cemas dan merasa terisolasi yang lebih intense pada orang tua yang anaknya terdiagnosa lebih dari 6 bulan. Berdasarkan nilai tertinggi dan terendah dapat dilihat pada anak yang terdiagnosis $0-6$ bulan terendah 51 dan tertinggi 63 bahwa memiliki rentan nilai total skor yang tinggi pada kelompok ini. Pada 2 kelompok responden standard deviasi lebih kecil dari mean menunjukan representasi nilai mean yang baik.

\section{Pembahasan}

Respon Anticipatory Grief Pada Orang Tua yang memiliki anak terdiagnosis 0-6 bulan dan $>6$ bulan.

Hasil penelitian (Tabel 1.2) menunjukan pada kelompok orang tua yang memiliki anak terdiagnosis $0-6$ bulan mengalami Anticipatory Grief yang lebih intens dari pada orang tua yang anaknnya terdiagnosis $>6$ bulan. Temuan ini sejalan dengan hasil penelitian di Jordania tahun 2010 yang menyatakan bahwa kelompok orang tua yang memiliki anak baru terdiagnosis mengalami Anticipatory Grief dengan hasil mean $=197.42$,SD $=20.53$ lebih tinggi dari orang tua yang memiliki anak terdiagnosa $>6$ bulan terdiagnosis yaitu mean = 163.15,SD=27.74 (Al-Gamal \& Long, 2010).

Perbedaan hasil mean kelompok orang tua yang memiliki anak terdiagnosis $0-6$ bulan dengan yang terdiagnosis $>6$ bulan tidak jauh signifikan sama halnya dengan hasil penelitian di Jordania tahun 2010. Hasil penelitian yang sejalan antara penelitian ini dengan hasil penelitian di Jordania tahun 2010 yaitu Anticipatory Grief yang lebih intens pada kelompok orang tua yang memiliki anak terdiagnosis $0-6$ bulan dapat terjadi karena pada fase awal 0-6 bulan adalah fase awal orang tua masih proses beradaptasi dengan penyakit anak dan takut akan ancaman kehilangan anak. Hal ini juga telah di jelaskan dalam penelitian Zeitlin (2010) bahwa respon Anticipatory Grief yang memiliki prolog $<12$ bulan, intense berduka yang tinggi pada orang tua yang memiliki anak terdiagnosis $0-6$ bulan terjadi karena respon Anticipatory Grief terhadap sebuah acaman kematian (Zeitlin, 2001). Hal ini terjadi mungkin dipengaruhi oleh beberapa faktor seperti lamanya terdiagnosis, pekerjaan, tingkat pendidikan orang tua. Berdasarkan Tabel 4.1 sebagian besar orang tua tidak berkerja, 
pada dimensi merasa sedih dan kehilangan.

\section{Respon Anticipatory Grief Dimensi Cemas Dan Merasa Terisolasi}

Berdasarkan tabel 4.6 pada dimensi cemas dan merasa terisolasi pada orang tua yang memiliki anak dengan leukemia limfoblastik Akut (LLA) di RSUP Dr Hasan Sadikin Bandung bahwa orang tua yang memiliki anak baru terdiagnosis memiliki intens berduka lebih tinggi dari kelompok orang tua yang memiliki anak terdiagnosis $>6$ bulan. Sesuai dengan Mauser dan Marwit dalam MMCGI menjelaskan tetang respon sosial atau cemas dan merasa terisolasi bahwa $85.7 \%$ orang tua yang anaknya baru terdiagnosis kanker merasa cemas akan masa depan merupakan score tertinggi dalam subcale cemas dan merasa takut.

Selain itu berdasarkan penyataan yang dialami orang tua yang memiliki anak terdiagnosis 0-6 bulan yaitu "saya merasa cemas dan takut" dimana rata-rata kelompok orang tua ini setuju dengan pernyataan tersebut. Hal ini menunjukan kecemasan yang dirasakan orang tua terkait kondisi anak serta kemungkinan berpisah dengan anak. Berbeda dengan kelompok orang tua yang memiliki anak terdiagnosis $>6$ bulan, pada dimensi ini orang tua dalam kondisi lebih damai dimana sesuai pernyataan "saya dapat mengelola secara keseluruhan dengan baik", dimana rata-rata orang tua setuju dengan pernyataan ini.

\section{Keterbatasan Penelitian}

Keterbatasan dalam penelitian ini yaitu masih terbatasnya jumlah sampel yang diambil dalam penelitian ini, yaitu 35 orang, walaupun peneliti sudah menerapkan teknik total sampling dalam pengambilan sampel dalam penelitian ini. Diharapkan untuk penelitian yang akan datang dapat memperbesar power sample dalam penelitian selanjutnya.

\section{Simpulan dan Saran}

Pada penelitian ini respon anticipatory grief pada kelompok orang tua yang memiliki anak baru terdiagnosis memiliki intense berduka lebih tinggi dari kelompok orang tua yang anaknya terdiagnosis sejak $>6$ bulan. Anticipatory grief terdiri dari 3 dimensi dimana pada penelitian ini dimensi Merasa sedih dan kehilangan merupakan dimensi tertinggi pada kedua kelompok orang tua. Adapun hasil penelitian ini dipisahkan antara kelompok orang tua yang memiliki anak baru terdiagnosis $(0-6$ bulan) dan kelompok orang tua yang anaknya terdiagnosis sejak $>6$ bulan di RSUP Dr Hasan Sadikin Bandung. Penelitian ini merekomendasikan agar perawat melakukan pengkajian yang komprehensif, termasuk pengkajian psikososial pada orangtua dengan anak kanker untuk memfasilitasi proses adaptasi pada orangtua dalam merawat anak kanker.

\section{Daftar pustaka}

Al-Gamal, E., \& Tony L. (2010). Anticipatory grieving among parents living with a child with cancer. Journal Of Advanced Nursing, 66(9): 1980-1990. 
Al-Gamal , E. (2013). Quality of life and Anticipatory grieving among parents living with a child with cerebral palsy. International Journal of Nursing Practice, 19(3): 288294.

Betz, C. L. (2009). Buku Saku Keperawatan Pediatri. Jakarta: EGC.

Burke, L., Clark , K., Ali, K., Gibson, B., Smigelsky, M., \& Neimeyer, R. (2015). Risk Factors for Anticipatory Grief in Family. Risk Factors for Anticipatory Grief in Family Members of Terminally Ill Veterans Receiving Palliative Care Services. J Soc Work End Life, 11(3): 244-266.

Fowler, R.N., Hansen, A.S., Barnato, A.E., \& Garand, L. (2013). Association between Anticipatory Grief and problem solving among family caregivers pf persons with cognitive impairment. $J$ Aging Health, 25(3): 493-509.

Fulton, R. (2003). Anticipatory mourning: a critique of the concept. Mortality, 8(4): 342351 .

Klassen, A., Klaassen, R., Dix, D., Pritchard, S., Yanofsky, R., O'Don, M., . . . Sung, L. (2008). Impact of Caring for a Child With Cancer on Parents' Health-Related Quality of Life. Journal Of Clinical Oncology, 26(36): 5884-5895.
Kubler-Ross, E. (1981). on Death and Dying. Britain: Social Science Paperback

Marwit, S. J., Cibhnal, J. T., Dougherty, R., Jenkins, C., \& Shawgo, J. (2008). Assessing pre-death Grief in cancer caregivers using the MarwitMeuser Caregiver Grief Inventory (MM-CGI). PsychoOncology, 17(3): 300-301.

Marwit, S. J., \& Meuser, T. M. ( 2005). Development Of A Short Form Inventory To Assess Grief In Caregivers Of Dementia Patients. Death Studies, 29(3): 191-205.

Puspita, S. K., \& Ludiro, S. K. (2013). Kondisi Orang Tua Pasien Kanker Anak Dilihat Dari Aspek Biopsikososial Berdasarkan Fase Pengobatan Anak (Studi Deskiptif Pada Support Group Sebagai Program Dalam Komunitas Pita Emas Rumah Sakit Kanker Dharmais Jakarta). Fakultas Ilmu Sosial dan Ilmu Politik, Jurusan Ilmu Kesejahteraan Sosial, Universitas Indonesia, Depok, Indonesia.

Rahmahkemala, R., Maslihah, S., \& Heryati, E. (2016). Hubungan Antara Anticipatory Grief Dengan Hope Dan Social Support Pada Orangtua Dari Anak Dengan Diagnosis Leukemia. UPI Digital Repository.

Simanjorang, C., Kodim, N., \& 
Tehuteru, E. (2012). Perbedaan Kesintasan 5 Tahun Pasien Leukemia Limfoblastik Akut dan Leukemia Mieblastik Akut pada Anak di Rumah Sakit Kanker "Dharmais". Indonesian Journal of Cancer, 6(2): $15-21$.

Valizadeh, L., Zamanzadeh, V., \& Rahiminia, E. (2013). Comparison of Anticipatory Grief reaction between fathers and mothers of premature infants in neonatal intensive care unit. Scandinavian Journal of Caring Sciences, 27(4): 921-926.

Zeitlin, S. (2001). Palliative Care. Washington: Mosby, Inc.

Wolfe, J, Klar, N., Grier, H.E., Duncan, J., Salem-Schats, S., Emanuel E.J., \& Weeks J.C. (2000). Understanding of prognosis among parents of children who died of cancer: impact on treatment goals and integration of palliative care. JAMA Journal, 15 (284), 24692475. 